\title{
INFLUENCE OF TRACK SHAPE RATIO ON TURNING CHARACTERISTICS OF A TRACKED VEHICLE RUNNING ON FRESH CONCRETE
}

\author{
Dang Thai TRAN ${ }^{1}$, Tatsuro MURO ${ }^{2}$, Soichiro KAWAHARA ${ }^{3}$ and Manabu HIRAKAWA ${ }^{4}$ \\ ${ }^{1}$ Student member of JSCE, M. Eng., Postgraduate Student, Graduate School of Science and Eng., Ehime University \\ (3 Bunkyo-cho Matsuyama 790-8577, Japan) \\ ${ }^{2}$ Fellow member of JSCE, Dr. Eng., Professor, Dept. of Civil and Environmental Eng., Ehime University \\ (3 Bunkyo-cho Matsuyama 790-8577, Japan) \\ ${ }^{3}$ Member of JSCE, Dr. Eng., Research Associate, Dept. of Civil and Environmental Eng., Ehime University \\ (3 Bunkyo-cho Matsuyama 790-8577, Japan) \\ ${ }^{4}$ Member of JSCE, M. Eng., Engineer, Hitachi Kenki Co. Ltd, \\ (650 Kamitachi-cho, Tsuchiura 300-0013, Japan)
}

\begin{abstract}
A simulation method was developed to investigate the possibility of economical adaptation of ordinary machinery to the work on fresh concrete by changing only track shape ratio. The simulation is then verified by an experiment on a model vehicle running on fresh concrete of slump of $5.5 \mathrm{~cm}$ with different traction force and with steering ratio of 1.6. Using the simulation, the influence of the track shape ratio on turning characteristics of tracked vehicle was investigated. The result of the investigation shows that, for a typical turning motion, the effective tractive effort decreases while the turning radius and turning moment increases with the increment of the track shape ratio.
\end{abstract}

Key Words: shape ratio, turning characteristics, tracked vehicle, fresh concrete

\section{INTRODUCTION}

The aim of the research is to investigate on a method to adapt ordinary tracked vehicle to a very soft terrain such as fresh concrete, soft sandy terrain or muddy terrain. As have been known, running characteristics are not only influenced by contact pressure but also by track shape ratio ${ }^{1)}$. Consequently, it can be expected that 'the most efficient and economic way to adapt ordinary tracked vehicle to weak terrain is to change only the vehicle undercarriage to reduce mean contract pressure. However, to further adapt the vehicle to super weak terrain, besides reducing mean contact pressure, there is a need to choose proper track shape ratio for that reduced mean contact pressure. By the selection of both the proper mean contact pressure and proper track shape ratio, with roughly the cost of the new track, it is expected that the vehicle can be adapted to a work requiring turning motion on very soft terrain environment. This paper presents the result of investigation of the effect of track shape ratio on turning characteristics of tracked vehicle while keeping reduced mean contact pressure unchanged by keeping constant mean contact area. Moreover, the track shape ratio was changed keeping the same grouser high and grouser pitch. Except for the change on track shape ratio by mean of change on track width and track length, other vehicle dimensions remain unchanged.

The comparison between turning proprieties of a model tracked vehicle running on the same fresh concrete with different track shape ratios shows that the track shape ratio has considerable effect on the running proprieties of tracked vehicles especially on the turning moment and turning radius. Based on the result of the investigation, it can be concluded that proper selection of the track shape ratio can improve the vehicle's workability on super weak terrain.

\section{SIMULATION}

(1) Forces and moment acting to turning vehicle

The vehicle is subjected to land locomotion resistances acting to outer and inner track $T_{20}$ and $T_{2 i}$. The direction of these forces is considered to be 


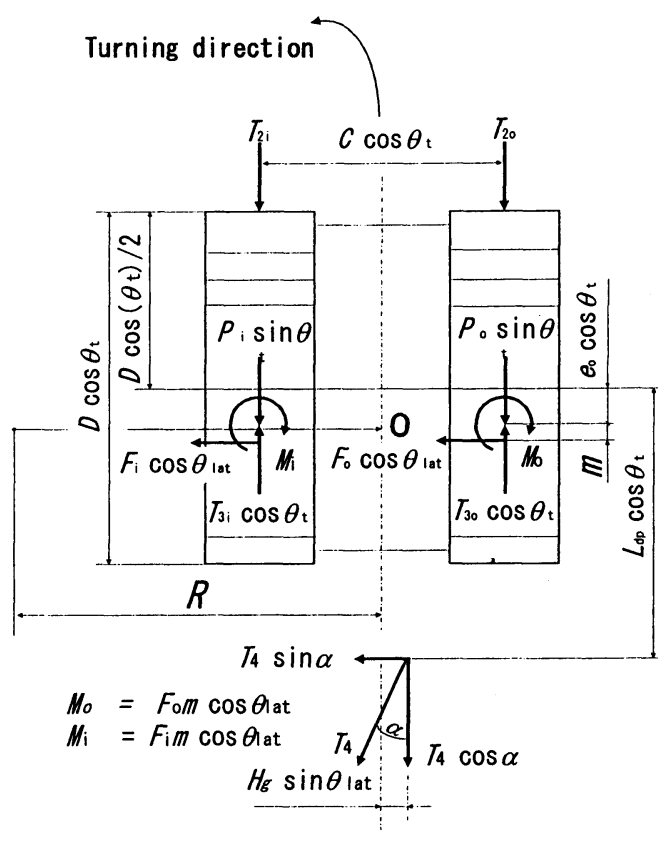

(a) Top view

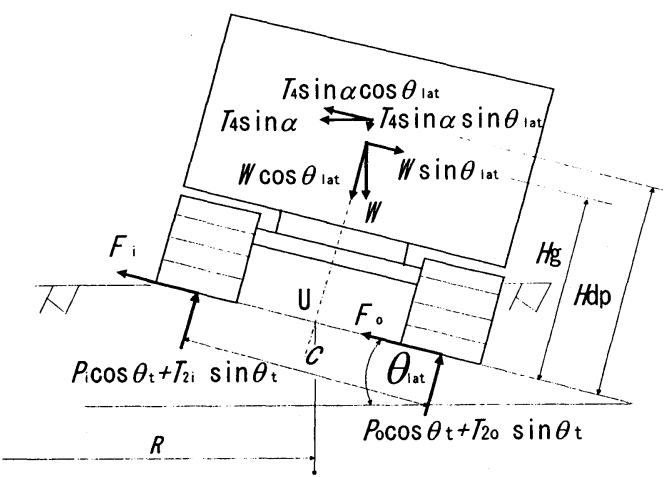

(b) Rear view

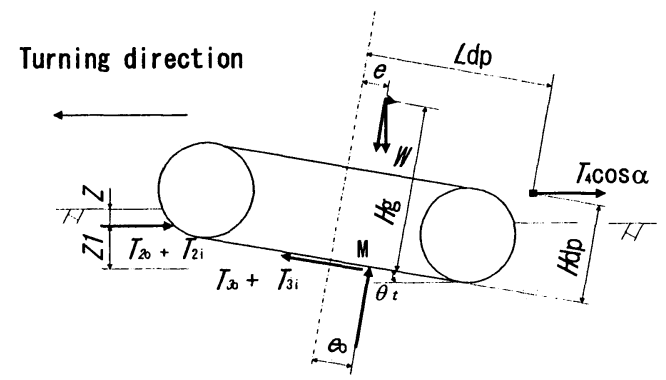

(c) Side view

Fig. 2 Forces and moment acting to turning vehicle

longitudinal. The direction of thrust of outer and inner track, $T_{30}$ and $T_{3 \mathrm{i}}$ is considered to be on the contact plane of the tracks. The resultant ground reactions $P_{\mathrm{o}}$ and $P_{\mathrm{i}}$ are considered having a normal direction to the contact plane of the tracks. The vehicle is subjected to lateral forces $F_{\mathrm{o}}$ and $F_{\mathrm{i}}$ caused by lateral bulldozing and lateral shear resistance. The turning moment $M$ is occurred to overcome the moment exerted by the resultant lateral force. The vehicle is also subjected to effective tractive effort $T_{4}$ and naturally to its own weight $W$. Fig. 1 shows the forces and moment acting to the turning vehicle. The equilibrium equations can be written as:

Force balance in the horizontal plane in longitudinal direction [Fig 1(a)]:

$$
\begin{gathered}
\left(T_{3 \mathrm{o}}+T_{3 \mathrm{i}}\right) \cos \theta_{\mathrm{t}}-\left(T_{2 \mathrm{o}}+T_{2 \mathrm{i}}\right) \\
-\left(P_{\mathrm{o}}+P_{\mathrm{i}}\right) \sin \theta_{\mathrm{t}}-T_{4} \cos \alpha=0
\end{gathered}
$$

Force balance in the vertical direction [Fig.1(b)]:

$$
\begin{gathered}
W-\left[\left(P_{\mathrm{o}}+P_{\mathrm{i}}\right) \cos \theta_{\mathrm{t}}+\left(T_{3 \mathrm{o}}+T_{3 \mathrm{i}}\right) \sin \theta_{\mathrm{t}}\right] \cos \theta_{\text {lat }} \\
-\left(F_{\mathrm{o}}+F_{\mathrm{i}}\right) \sin \theta_{\text {lat }}=0
\end{gathered}
$$

Force balance in the horizontal plane in lateral direction [Fig.1(a)]:

$$
\begin{gathered}
T_{4} \sin \alpha+\left(F_{\mathrm{o}}+F_{\mathrm{i}}\right) \cos \theta_{\text {lat }} \\
-\left(P_{\mathrm{o}}+P_{\mathrm{i}}\right) \cos \theta_{\mathrm{t}} \sin \theta_{\text {lat }}=0
\end{gathered}
$$

Moment balance written for point U [Fig. 1(b)]:

$$
\begin{gathered}
\frac{C}{2}\left[\left(P_{\mathrm{o}}-P_{\mathrm{i}}\right)+\left(T_{20}-T_{2 \mathrm{i}}\right) \sin \theta_{\mathrm{t}}\right] \\
-W H_{\mathrm{g}} \sin \theta_{\text {lat }} \cos \theta_{\mathrm{t}}+\mathrm{T}_{4} H_{\mathrm{dp}} \sin \alpha \cos \theta_{\text {lat }}=0
\end{gathered}
$$

Moment balance in horizontal plane [Fig. 1(a)]:

$$
\begin{aligned}
M+ & \left(T_{20}+P_{\mathrm{o}} \sin \theta_{\mathrm{t}}-T_{3 \mathrm{o}} \cos \theta_{\mathrm{t}}\right) \frac{C}{2} \cos \theta_{\text {lat }} \\
- & \left(T_{2 \mathrm{i}}+P_{\mathrm{i}} \sin \theta_{\mathrm{t}}-T_{3 \mathrm{i}} \cos \theta_{\mathrm{t}}\right) \frac{C}{2} \cos \theta_{\text {lat }} \\
+ & T_{4} \sin \alpha \cos \theta_{\mathrm{t}}\left[L_{\mathrm{dp}}-\left(e_{\mathrm{o}}+e_{\mathrm{i}}\right) \frac{d}{2}\right] \\
& +T_{4} \cos \alpha H_{\mathrm{dp}} \sin \theta_{\text {lat }}=0
\end{aligned}
$$

Where

$T_{20}, T_{2 \mathrm{i}}$ : Land locomotion resistance of outer and inner track

$T_{30}, T_{3 \mathrm{i}}$ : Thurst of outer and inner track.

$P_{\mathrm{o}}, P_{\mathrm{i}}$ : Ground reaction of outer and inner track.

$M$ : $\quad$ Turning moment.

$T_{4}: \quad$ Effective tractive effort. 


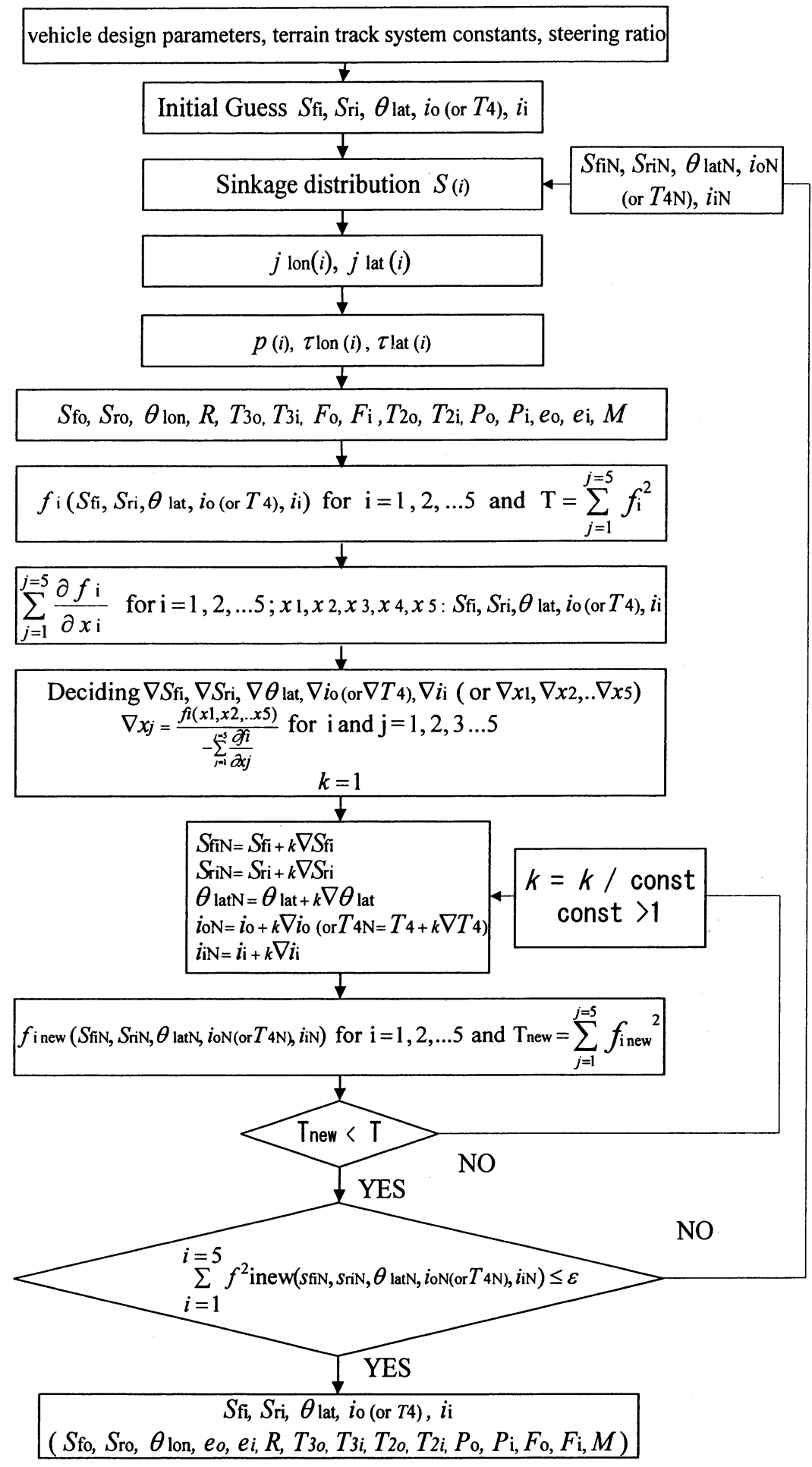

Fig. 2 Simulation flow chart 


\section{(2) Simulation method and flow-chart}

For tracked vehicle with rigid suspension system the set of equations describing the state of steady turning can be collapsed into the set of 5 equilibrium equations $(1) \sim(5)$ with 5 independent unknowns ${ }^{2)}{ }^{3)}$. The independent unknowns are sinkage of front idler and rear sprocket of inner track $S_{\mathrm{fi}}, S_{\mathrm{ri}}$, lateral inclination angle $\theta_{\text {lat }}$, slip ratio of outer track $i_{\mathrm{o}}$ (or effective tractive effort $T_{4}$ ) and slip ratio of inner track $i_{i}$. For flexible tracked vehicle with rigid suspension system, all other characteristics in the set of equilibrium equations; turning moment $M$, thrusts of outer and inner track $T_{30}, T_{3 \mathrm{i}}$, lateral forces $F_{\mathrm{o}}, F_{\mathrm{i}}$, land locomotion resistances $T_{2 \mathrm{o}}, T_{2 \mathrm{i}}$, ground reactions $P_{\mathrm{o}}, P_{\mathrm{i}}$, turning radius $R$, eccentricities $e_{\mathrm{o}}, e_{\mathrm{i}}$, angle of inclination of vehicle $\theta_{\mathrm{t}}$, can be computed from the above 5 independent unknowns. Consequently, the balance conditions for the arbitrary set of the unknowns can be investigated and the unknowns can be methodically modified to satisfy the balance conditions. Using this approach, the problem of predicting turning characteristics can be expressed as problem of finding out which combination of the position of the vehicle at steady turning state (specified by $S_{\mathrm{fi}}, S_{\mathrm{ri}}$ and $\theta_{\text {lat }}$ ) and operating conditions (specified by $i_{0}$ (or $T_{4}$ ) and $i_{\mathrm{i}}$ ) satisfies the equilibrium equations. The answer to this problem is to solve the set of 5 equilibrium equations for the 5 unknowns $S_{\mathrm{fi}}, S_{\mathrm{ri}}, \theta_{\text {lat }}, i_{\mathrm{o}}\left(\right.$ or $T_{4}$ ) and $i_{\mathrm{i}}$. Newton-Raphson method for a set of nonlinear equations is used as a solving method of this set of nonlinear equations ${ }^{4)}$. As a result, the flow chart of the simulation is as shown in Fig.2.

At first, the design parameters of vehicle, terraintrack system constants and steering ratio are inputted into the simulation. Then the initial guess of $S_{\mathrm{fi}}, S_{\mathrm{ri}}, \theta_{\text {lat }}, i_{\mathrm{o}}$ (or $T_{4}$ ) and $i_{\mathrm{i}}$ are selected and inputted into the program. As the next steps the sinkage distribution $S(\mathrm{i})$, distribution of longitudinal and lateral amount of slippage $J_{\text {lon }}(i)$ and $J_{\text {lat }}(i)$, pressure distributions $p(\mathrm{i})$, longitudinal and lateral shear distribution $\tau_{\text {lon }}, \tau_{\text {lat }}$ are calculated. Based on the above calculated values all the characteristics that appear in the set of equilibrium equations; $M$, $T_{30}, T_{3 \mathrm{i}}, F_{\mathrm{o}}, F_{\mathrm{i}}, T_{2 \mathrm{o}}, T_{2 \mathrm{i}}, P_{\mathrm{o}}, P_{\mathrm{i}}, R, e_{\mathrm{o}}, e_{\mathrm{i}}, \theta_{\mathrm{t}}$, are computed using basic equations of terrain-track interaction and other equations of geometrical relationship between those characteristics ${ }^{5}$. The equilibrium conditions of the set of the guess of $S_{\mathrm{fi}}$, $S_{\mathrm{ri}}, \theta_{\mathrm{lat}}, i_{\mathrm{o}}$ (or $T_{4}$ ) and $i_{\mathrm{i}}$ can then be investigated by replacing the above calculated characteristics into the left hand side of the equilibrium equations. If the equilibrium conditions are not satisfied the
Table 1 Properties of artificial fresh concrete

\begin{tabular}{|c|c|c|c|c|}
\hline $\begin{array}{l}\text { Max. } \\
\text { Aggr. } \\
(\mathrm{mm})\end{array}$ & $\begin{array}{l}\text { Air } \\
\text { cont. } \\
(\%)\end{array}$ & $\begin{array}{l}\text { Water- } \\
\text { Cement } \\
\text { Ratio } \\
(\%)\end{array}$ & $\begin{array}{l}\text { Admixt } \\
\text {-ures } \\
\text { ratio } \\
(\%)\end{array}$ & $\begin{array}{l}\text { Slump } \\
(\mathrm{cm})\end{array}$ \\
\hline 13 & 2.5 & 53 & 52 & 5.5 \\
\hline $\begin{array}{l}\text { Water } \\
\text { content } \\
\left(\mathrm{kg} / \mathrm{m}^{3}\right)\end{array}$ & $\begin{array}{l}\text { Clay } \\
\text { Content } \\
\left(\mathrm{kg} / \mathrm{m}^{3}\right)\end{array}$ & $\begin{array}{l}\text { Admix- } \\
\text { tures } \\
\text { content } \\
\left(\mathrm{kg} / \mathrm{m}^{3}\right)\end{array}$ & $\begin{array}{l}\text { Aggreg } \\
\text { ate } \\
\text { content } \\
\left(\mathrm{kg} / \mathrm{m}^{3}\right)\end{array}$ & $\begin{array}{l}\text { Stabili- } \\
\mathrm{zer} \\
\left(\mathrm{kg} / \mathrm{m}^{3}\right)\end{array}$ \\
\hline 203.6 & 307.5 & $\mathbf{8 9 7 . 8}$ & $\mathbf{8 3 1 . 9}$ & 1.158 \\
\hline
\end{tabular}

corrected values of the guessed unknown are then computed using Newton-Raphson method. Using the above corrected values of $S_{\mathrm{fi}}, S_{\mathrm{ri}}, \theta_{\text {lat }}, i_{\mathrm{o}}$ (or $T_{4}$ ) and $i_{\mathrm{i}}$ the calculation is repeated until convergence.

\section{EXPERIMENT}

The experiment on model vehicle turning on fresh concrete was carried out to verify the simulation analysis. Artificial fresh concrete using clay instead of cement is used to avoid hardening of the material during experiment. Table 1 shows properties of the artificial concrete.

Fig. 3 shows the outline of the model vehicle. The model vehicle is $1 / 10$ scale model of the $40 \mathrm{kN}$ bulldozer running on soft sandy terrain. The model vehicle is made for the purpose of verification of the simulation analysis, therefore, the exact modeling is not of first priority. The track mean contact pressure was modified to the pressure of $0.483 \mathrm{~N} / \mathrm{cm}^{2}$ which is lower then that for super weak terrain to make the vehicle suitable for running on fresh concrete of slump of $5.5 \mathrm{~cm}$. It must be noted that the above contact pressure is selected to investigate the effect of track shape ratio for that pressure and the thorough investigation on appropriate selection of mean contact pressure is not of concern of this paper. Each of the tracks of the vehicle is driven independently by a $90 \mathrm{~W}$ AC motor through chain transmission. Rotary speed of the main shaft of the motors can be set at fixed value by speed regulators so that steering ratio could be adjusted. Three road rollers support each of the track belts. The dimension of model vehicle is shown in Table 2.

Table 3 shows the terrain-track system constants determined by plate loading unloading and traction test ${ }^{4)}$. The constants $k_{1}, n_{1}, k_{2}, n_{2}$ determined the 

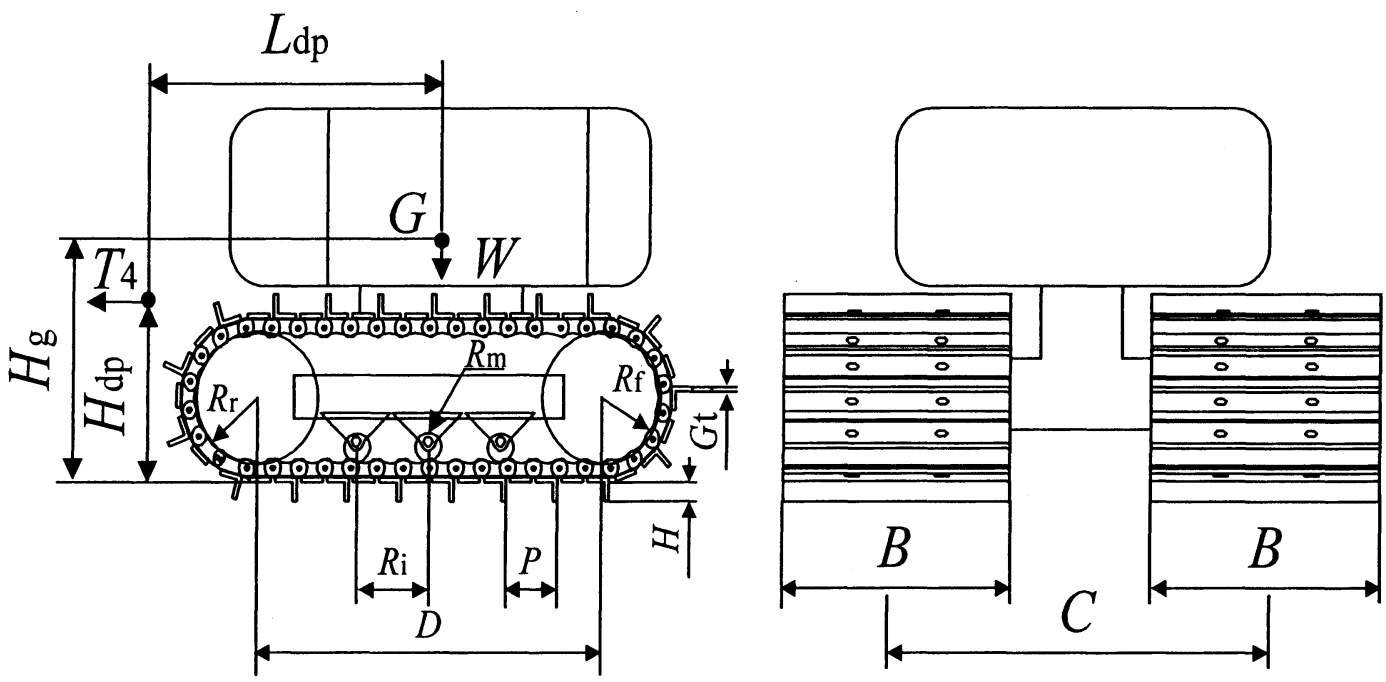

Fig. 3 Outline of model vehicle

Table 2 Model vehicle dimension

\begin{tabular}{|l|r|l|r|}
\hline Vehicle weight $W(\mathrm{~N})$ & 638 & Grouser height $H(\mathrm{~cm})$ & 1.7 \\
\hline Height of hitch point $H_{\mathrm{dp}}(\mathrm{cm})$ & 15 & Grouser pitch $P(\mathrm{~cm})$ & 2.55 \\
\hline Dist. cent. of grav.-hitch point $L_{\mathrm{dp}}(\mathrm{cm})$ & 30 & Grouser thickness $G \mathrm{t}(\mathrm{cm})$ & 0.3 \\
\hline Initial track tension $H \mathrm{o}(\mathrm{N})$ & 196 & Maximum track deflection $(\mathrm{cm})$ & 1 \\
\hline Height of center of gravity $H \mathrm{~g}(\mathrm{~cm})$ & 10 & Radius of front idler $R_{\mathrm{f}}(\mathrm{cm})$ & 6.5 \\
\hline Contact length $D(\mathrm{~cm})$ & 33 & Radius of rear sprocket $R_{\mathrm{r}}(\mathrm{cm})$ & 6.5 \\
\hline Track width $B(\mathrm{~cm})$ & 20 & Radius of road rollers $R_{\mathrm{m}}(\mathrm{cm})$ & 1.9 \\
\hline Mean contact pressure $(\mathrm{kPa})$ & 4.83 & Number of road rollers & 3 \\
\hline Track gauge $C(\mathrm{~cm})$ & 33 & Road roller interval $R \mathrm{i}(\mathrm{cm})$ & 6 \\
\hline
\end{tabular}

relationship between contact pressure $p$ and slip sinkage $s$ as in the following formula for the case when there is no rebound sinkage:

$$
p=k_{1} s^{n 1}
$$

Where $p$ contract pressure

$$
s \text { sinkage of track }
$$

For the case when there is rebound sinkage, the relationship between contact pressure and sinkage is determined by:

$$
p=k_{1} s^{n 1}+k_{2}(s-H)^{n 2}
$$

Where $H$ is the sinkage of the beginning of the rebound process ${ }^{4)}$.

The terrain-track system constants determined form traction test, $m_{\mathrm{c}}, m_{\mathrm{f}}$ and $a, c_{0}, c_{1}, c_{2}$, describe the relationship between shear resistance and amount of slippage and relationship among slip sinkage, contract pressure and amount of slippage as in the following formulas:
Table 3 Terrain-track system constants

\begin{tabular}{|c|c|c|c|}
\hline & $\begin{array}{c}m_{\mathrm{c}} \\
\left(\mathrm{N} / \mathrm{cm}^{2}\right)\end{array}$ & $m_{\mathrm{f}}$ & $a(1 / \mathrm{cm})$ \\
\hline Lon. & 0.0157 & 1.0170 & 0.1531 \\
\hline Lat. & 0.1236 & 1.0170 & 0.1225 \\
\hline $\begin{array}{c}k_{1} \\
\left(\mathrm{~N} / \mathrm{cm}^{\mathrm{n} 1+2}\right)\end{array}$ & $n_{1}$ & $\begin{array}{c}k_{2} \\
\left(\mathrm{~N} / \mathrm{cm}^{\mathrm{n} 1+2}\right)\end{array}$ & $n_{2}$ \\
\hline 0.2276 & 1.2130 & 8.5445 & 0.8010 \\
\hline$c_{0}\left(\mathrm{~cm}^{1+2 \mathrm{cl}-\mathrm{c}^{2}} / \mathrm{N}^{\mathrm{cl}}\right)$ & $c_{1}$ & $c_{2}$ \\
\hline \multicolumn{2}{|c|}{0.9262} & 0.9151 & 0.6006 \\
\hline
\end{tabular}

$$
\begin{gathered}
\tau=\left(m_{\mathrm{c}}+m_{\mathrm{f}} \cdot p\right)[1-\exp (-a \cdot j)] \\
s=c_{\mathrm{o}} p^{c 1} j^{c 2}
\end{gathered}
$$

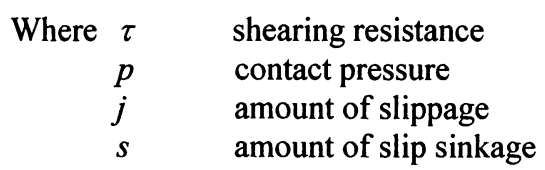




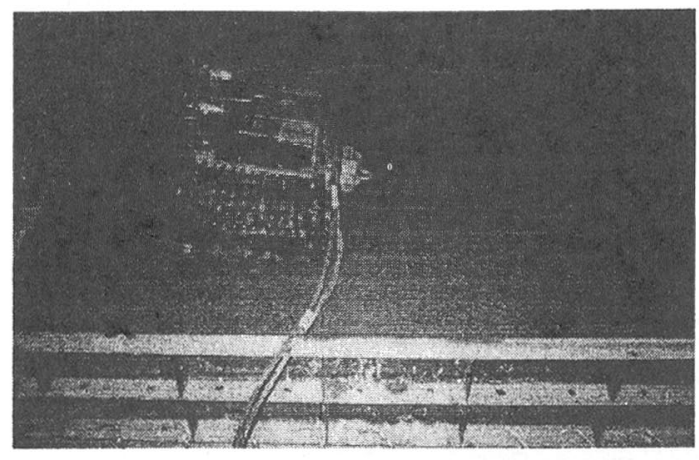

Fig. 4 Turning experiment

The vehicle is run in a soil bin with steering ratio of 1.6 (Fig. 4). The steering ratio is defined by the ratio of circumferential speed of outer to that of the inner track. The experiment was carried out for three cases of effective tractive effort of 0,69 and $147 \mathrm{~N}$.

The soil bin has a width and length of $270 \mathrm{~mm}$ and depth of $30 \mathrm{~mm}$. Due to the fact that, for all the cases of experiment, front idler of both tracks are in state of floating above concrete, the effect of reaction force from boundary of soil bin due to bulldozing resistance can be ignored.

Directly measured parameters are sinkages, traveled distances covered by each track, time during which these distances are covered, effective tractive effort, and rotary speed of each track. The sinkages were measured using a depth gauge while the traveled distances by a distance measurer. The sinkage was measured immediately after the vehicle is stopped to reduce errors between moving and stopped vehicle due to rebound of fresh concrete. The developed traction force is recorded using a load cell and a universal memorizer. The rotary speeds are measured using a speed measurement device. From the directly measured parameters the turning radius and the slip ratio of each track were determined.

\section{RESULTS AND DISCUSSION}

\section{(1) Research conditions}

The experiment was carried out with only one case of track shape ratio $k$ of 1.650 while the simulation was carried out for different track shape ratios $k$ defined as:

$$
k=\frac{D}{B}
$$

Where $B$ is the track width and $D$ is the track contact length (Fig. 3).
Table 4 Track shape ratio cases

\begin{tabular}{|c|c|c|c|}
\hline$B(\mathrm{~cm})$ & $D(\mathrm{~cm})$ & $k$ & $\begin{array}{c}p_{\text {mean }}=W / 2 B D \\
\left(\mathrm{~N} / \mathrm{cm}^{2}\right)\end{array}$ \\
\hline 12.50 & 52.80 & 4.224 & 0.483 \\
\hline 13.75 & 48.00 & 3.491 & 0.483 \\
\hline 15.00 & 44.00 & 2.933 & 0.483 \\
\hline 16.00 & 41.25 & 2.578 & 0.483 \\
\hline 20.00 & 33.00 & 1.650 & 0.483 \\
\hline
\end{tabular}

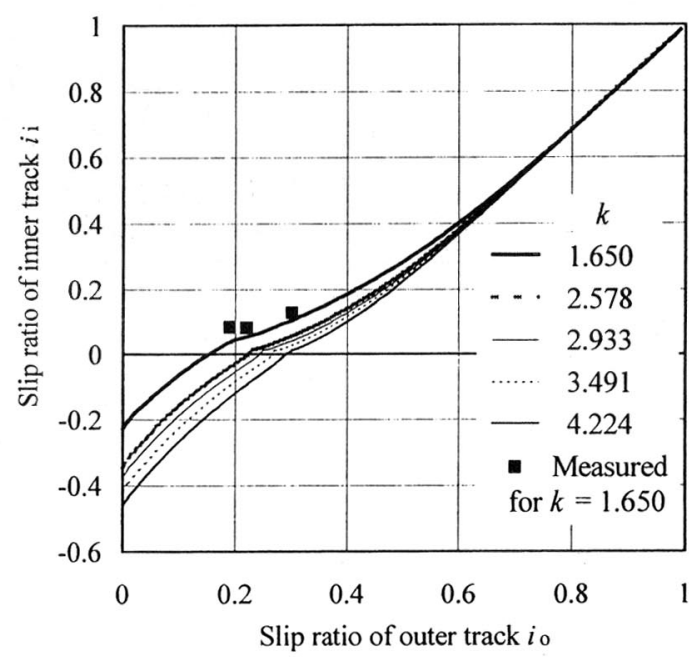

Fig. 5 Influence of track shape ratio $k$ on slip ratio of inner track $i_{\mathrm{i}}$ for different slip ratios of outer track $i_{0}$

Table 4 shows the cases of investigated track shape ratio. The simulation was carried out with the track shape ratio $k$ of $4.244,3.491,2.933,2.578$ and 1.650. The mean contact pressure $P_{\text {mean }}$ is kept unchanged by keeping constant mean contact area $B \times D$. Except for the change of the track width $B$ and the contact length $D$ to modify track shape ratio $k$, other vehicle specifications are unchanged. For each of the track shape ratio $k$ the simulation was carried out to compute turning characteristics of the vehicle turning with steering ratio of 1.6 for slip ratio of outer track $i_{0}$ ranging from 0 to 1 with step of 0.01 .

\section{(2) The effect of the track shape ratio on running characteristics}

The change of the track shape ratio $k$ will bring about the change of the actual contact area even if the mean contact area $B \times D$, which is used as one of the important design parameter, remains unchanged. The track shape ratio $k$ exerts its influences on turning characteristics of tracked vehicle through its effect on the change of actual contact area and through its effect on land locomotion resistance.

Fig. 5 shows the influence of the shape ratio $k$ on slip ratio of inner track $i_{\mathrm{i}}$ for different slip ratios of 


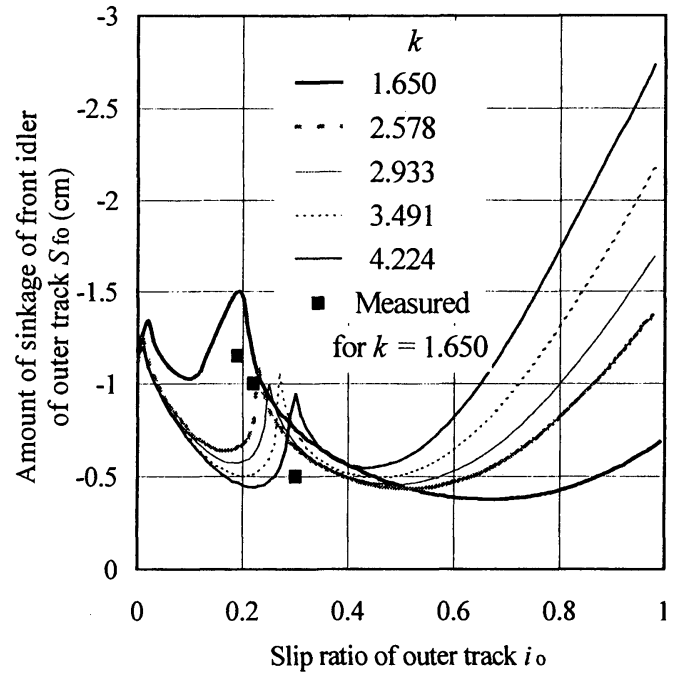

Fig. 6 Influence of track shape ratio $k$ on amount of sinkage of front idler of outer track $s_{\mathrm{fo}}$ for different slip ratios of outer track $i_{\mathrm{o}}$

outer track $i_{0}$. The slip ratio of outer track $i_{0}$ and inner track $i_{0}$ are slip ratios in horizontal direction. The slip ratio of inner track $i_{\mathrm{i}}$ increases with the decrement of track shape ratio $k$, i.e. increment of track width $B$. Moreover, the degree of influence of track shape ratio $k$ decreases as the slip ratio of outer track $i_{0}$ increases. For smaller range of slip ratios of outer track $i_{0}$ the influence of the track shape ratio $k$ is considerable while from the slip ratios of outer track $i_{\mathrm{o}}$ of about 0.6 this influence becomes very small. The figure also shows the comparison between measured and calculated values of the slip ratio of inner track $i_{\mathrm{i}}$ for the case of the track shape ratio $k$ of 1.650. The comparison shows good match between computed and measured values.

Fig. 6 shows the influence of the track shape ratio $k$ on the sinkage of front idler of outer track $S_{\mathrm{fo}}$ for different slip ratios of outer track $i_{0}$. The influence of the track shape ratio $k$ on the sinkage of front idler of outer track $S_{\mathrm{fo}}$ can be said rather complex as can be seen from the figure. For a bigger range of slip ratio of outer track $i_{0}$, the sinkage of front idler of outer track $S_{\text {fo }}$ decreases. The figure also shows the comparison between measured and calculated values of the sinkage of front idler of outer track $S_{\mathrm{fo}}$ for the case of shape ratio $k$ of 1.650 . The figure shows that the measured and calculated values agree well with each other.

Fig. 7 shows the influence of the track shape ratio $k$ on the sinkage of rear sprocket of outer track $S_{\text {ro }}$ for different slip ratios of outer track $i_{0}$. In general the sinkage of rear sprocket of outer track $S_{\text {ro }}$

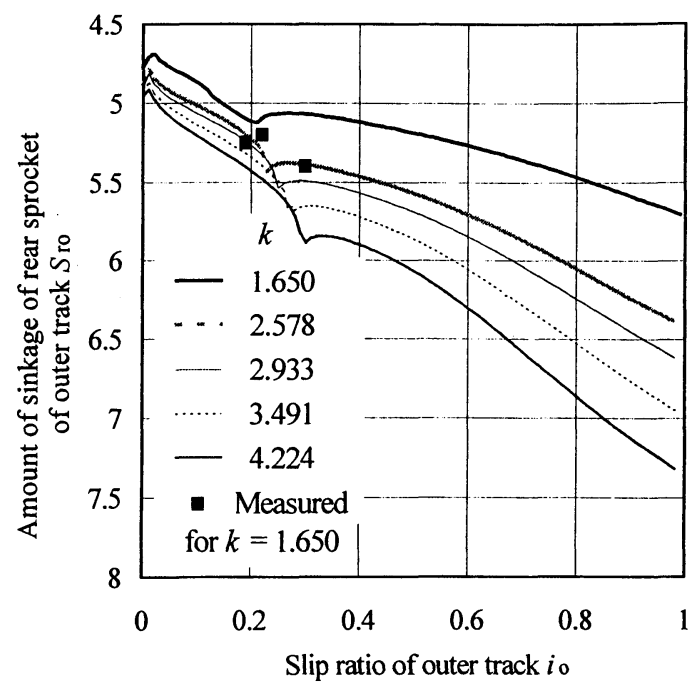

Fig. 7 Influence of track shape ratio $k$ on amount of sinkage of rear sprocket of outer track $s_{\mathrm{ro}}$ for different slip ratios of outer track $i_{\text {o }}$

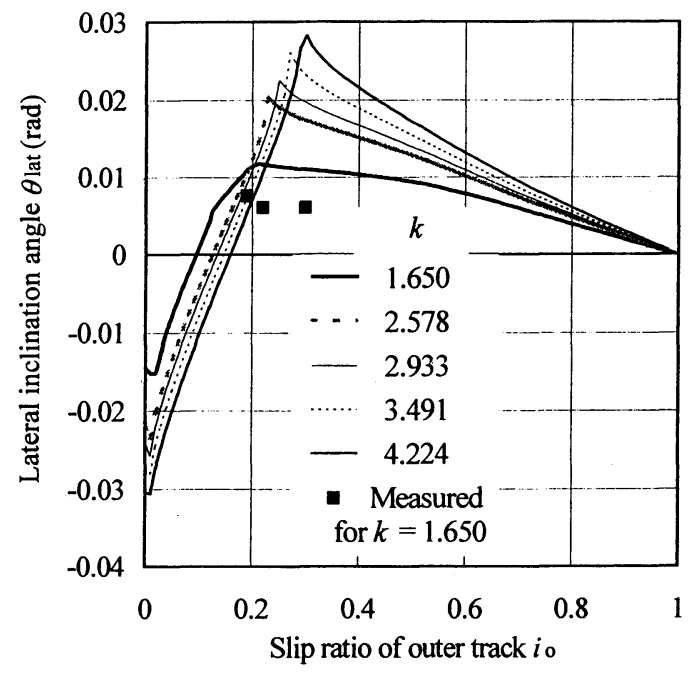

Fig. 8 Influence of track shape ratio $k$ on lateral inclination angle $\theta_{\text {lat }}$ for different slip ratios of outer track $i_{\mathrm{o}}$

increases with the increment of slip ratio of outer track $i_{0}$. Moreover, the sinkage of rear sprocket of outer track $S_{\text {ro }}$ increases with the increment of shape ratio $k$, i. e. with decrement of track width $B$. The degree of influence of track shape ratio $k$ on the sinkage of rear sprocket of outer track $S_{\text {ro }}$ is significant and increases with the increment of slip ratio of outer track $i_{0}$. The figure also shows the verification result of the simulation program by experimental results for the case of shape ratio of 1.650 .

Fig. 8 shows the influence of the track shape ratio $k$ on lateral trim angle $\theta_{\text {lat }}$ for different slip ratios of 


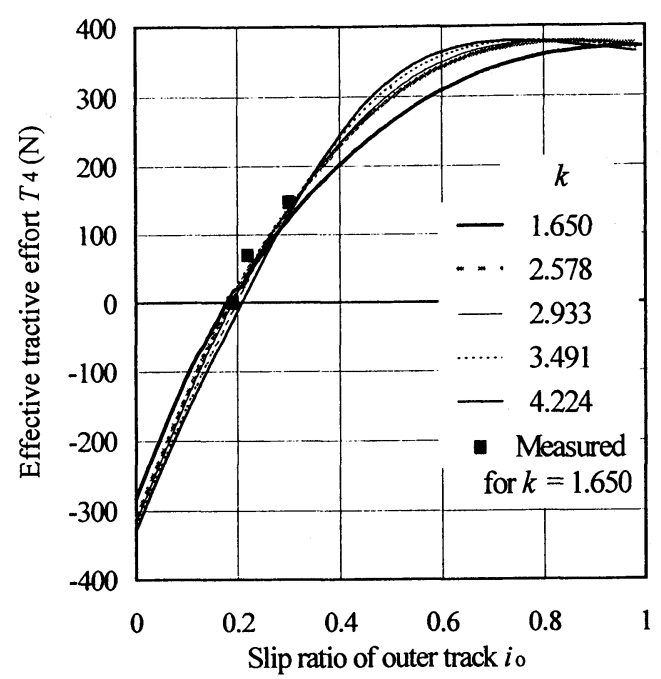

Fig. 9 Influence of track shape ratio $k$ on effective tractive effort $T_{4}$ for different slip ratios of outer track $i_{\mathrm{o}}$ outer track $i_{0}$. The figure shows that the influence of track shape ratio $k$ on lateral trim angle $\theta_{\text {lat }}$ is rather complex. The figure also shows the comparison between measured and calculated values of lateral trim angle $\theta_{\text {lat }}$ for the case of track shape ratio of 1.650. The comparison shows good match between measured and calculated values.

Fig. 9 shows the influence of the track shape ratio $k$ on the effective tractive effort $T_{4}$. In general, the tractive effort $T_{4}$ decreases with the increment of the track shape ratio $k$, i.e. decrement of the track width $B$ for a typical turning motion corresponding to the region of smaller slip ratio of outer track $i_{0}$. Contrary, the tractive effort $T_{4}$ increases with the increment of the track shape ratio $k$, i.e. decrement of the track width $B$ in the region of bigger slip ratio of outer track $i_{\mathrm{o}}$. The figure shows there exists maximum effective tractive effort $T_{4}$ for all the cases of the track shape ratio $k$. The figure also shows the comparison between measured and computed values of the effective tractive effort for the case of track shape ratio of 1.650 , i.e. track width of $20.00 \mathrm{~cm}$. The comparison shows rather good match between simulation and experimental results.

Fig. 10 shows the influence of the track shape ratio $k$ on the thrust of outer track $T_{30}$ for different slip ratios of outer track $i_{0}$. The thrust of outer $T_{30}$ achieves maximum values for all the cases of the track shape ratio $k$. Moreover, the thrust of outer track $T_{30}$ decreases with the decrement of shape ratio $k$, i.e. the increment of track width $B$. The influence of the track shape ratio $k$ on the thrust of outer track $T_{30}$ is considerable, considering that the change on the track shape ratio $k$ is relatively small.

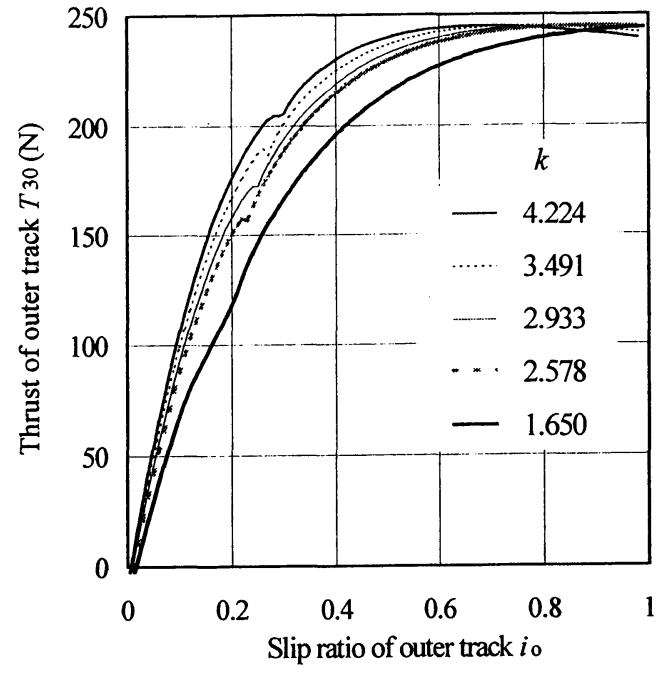

Fig. 10 Influence of track shape ratio $k$ on thrust of outer track $T_{30}$ for different slip ratios of outer track $i_{\mathrm{o}}$

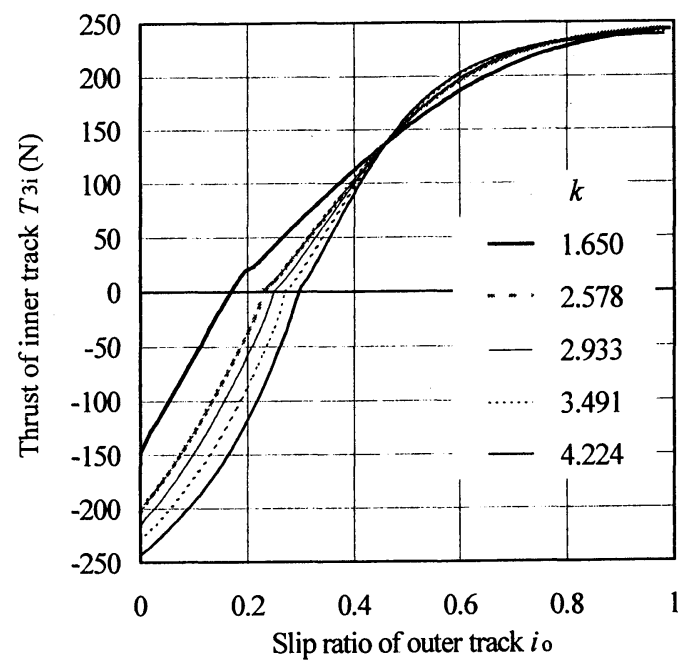

Fig. 11 Influence of track shape ratio $k$ on thrust of inner $\operatorname{track} T_{3 \mathrm{i}}$ for different slip ratios of outer track $i_{\mathrm{O}}$

Fig. 11 shows the influence of the track shape ratio $k$ on the thrust of inner track $T_{3 i}$ for different slip ratios of outer track $i_{0}$. In the larger zone of the slip ratio of outer track $i_{0}$ the thrust of inner track $T_{3 \mathrm{i}}$ decreases with decrement of the track shape ratio $k$, i.e. increment of the track width $B$. In the smaller zone of the slip ratio of outer track $i_{0}$, however, the reversed tendency can be observed, i.e. the thrust of inner track $T_{3 \mathrm{i}}$ increases with decrement of the track shape ratio $k$, i.e. increment of the track width $B$. The figure shows that the track shape ratio $k$ exerts considerable effect on the thrust of inner track $T_{3 \mathrm{i}}$. 


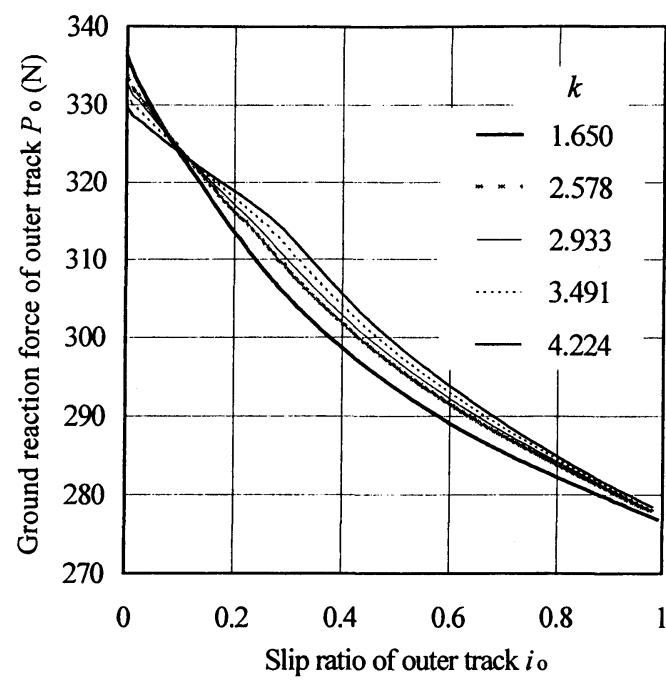

Fig. 12 Influence of track shape ratio $k$ on ground reaction force of outer track $P_{\mathrm{o}}$ for different slip ratios of outer track $i_{\mathrm{o}}$

Fig. 12 shows the influence of the track shape ratio $k$ on the ground reaction force of outer track $P_{\mathrm{o}}$ for different slip ratios of outer track $i_{0}$. The influence of the track shape ratio $k$ on ground reaction force of outer track $P_{\mathrm{o}}$ is complex and different depending on the value of the slip ratio of outer track $i_{0}$. In the region of larger value of the slip ratio of outer track $i_{\mathrm{o}}$ the ground reaction force of outer track $P_{\mathrm{o}}$ increases with the increment of the track shape ratio $k$, i.e. decrement of the track width $B$. Contrary, for a region where the slip ratio of outer track $i_{\mathrm{o}}$ has smaller values the ground reaction force of outer track $P_{0}$ increases with decrement of the track shape ratio $k$, i.e. decrement of the track width $B$. The figure shows considerable effect of the track shape ratio $k$ on the ground reaction force of outer track $P_{\mathrm{o}}$.

Fig. 13 shows the influence of the track shape ratio $k$ on the ground reaction force of inner track $P_{\mathrm{i}}$ for different slip ratios of outer track $i_{\mathrm{o}}$. Similarly to the case of the ground reaction force of the outer track $P_{\mathrm{o}}$, the ground reaction of inner track $P_{\mathrm{i}}$ decreases with increment of the slip ratio of outer track $i_{0}$ for all the cases of track shape ratio $k$. Furthermore, the ground reaction of inner track $P$ increases with increment of the track shape ratio $k$, i .e. decrement of the track width $B$.

Fig. 14 shows the influence of the track shape ratio $k$ on the turning moment $M$ for different slip ratios of outer track $i_{0}$. The track shape ratio $k$ exerts considerable influence on the turning moment $M$ in the region of typical turning motion with smaller slip ratio of outer track $i_{0}$. Furthermore, the turning

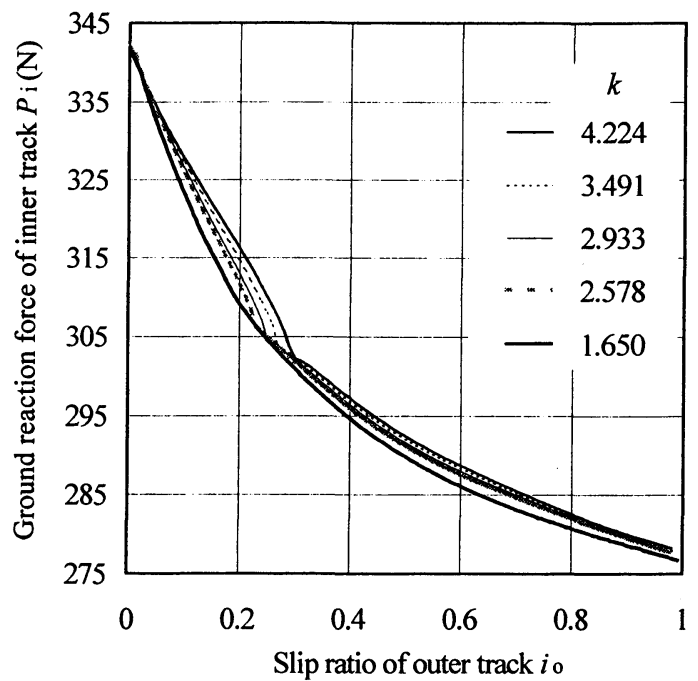

Fig. 13 Influence of track shape ratio $k$ on ground reaction force of inner track $P_{\mathrm{i}}$ for different slip ratios of outer track $i_{\mathrm{o}}$

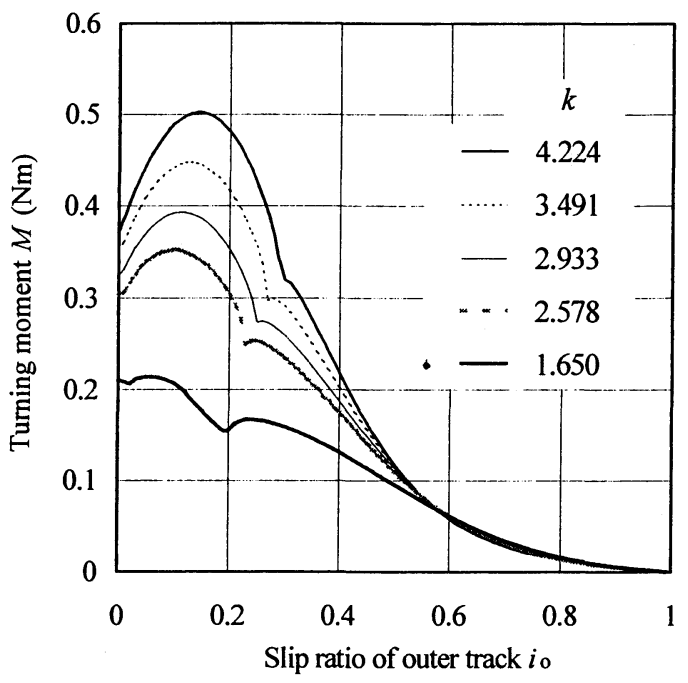

Fig. 14 Influence of track shape ratio $k$ on turning moment $M$ for different slip ratios of outer track $i_{\mathrm{o}}$

moment $M$ increases with the increment of the track shape ratio $k$, i. e. decrement of the track width $B$. This phenomenon can be explained by decrease of arm length and lateral bulldozing resistance due to the decrease of the contact length when the track width increases. The maximum turning moment $M$ can be observed for all the cases of the track shape ratio $k$. The turning moment $M$ of track shape ratio of 4.244 , i.e. track width of $12.5 \mathrm{~cm}$ is about from 2 to 3 times that of the turning moment $M$ of track shape ratio of 1.650 , i.e. track width of $20 \mathrm{~cm}$. As a result, it can be concluded that the track shape ratio 


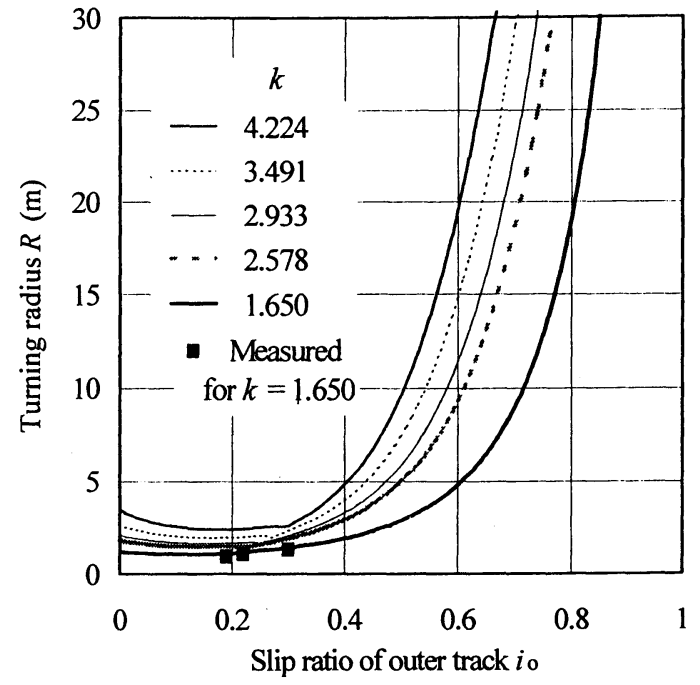

Fig. 15 Influence of track shape ratio $k$ on turning radius $R$ for different slip ratios of outer track $i_{o}$

$k$ plays a very important role in the design of tracked vehicles working on a soft terrain.

Fig. 15 shows the influence of the track shape ratio $k$ on the turning radius $R$ for different slip ratios of outer track $i_{0}$. For better comparison between turning radius $R$ of different track shape ratios $k$, the range of turning radius $R$ is limited to the range from 0 to $30 \mathrm{~m}$. The turning radius $R$ increases with the increment of the track shape ratio $k$, i. e. the decrement of the track width $B$. From the figure, it can be observed that the track shape ratio $k$ exerts considerable influence on the turning radius $R$ especially in the larger range of the slip ratio of outer track $i_{0}$. The figure shows the minimum value of turning radius $R$ can be observed for all the cases of shape track ratio $k$. It is obvious that the turning radius $R$ increases very rapidly from certain slip ratio of outer track $i_{0}$. The figure also shows the comparison between measured and calculated turning radius $R$ for the case of the track shape ratio $k$ of 1.650 , i.e the track width $B$ of $20 \mathrm{~cm}$. The comparison shows that the measured and calculated values of turning radius $R$ agree well with each other.

Fig. 16 shows the influence of the track shape ratio $k$ on the input energy $E_{1}$ for different slip ratios of outer tracks $i_{0}$. For better comparison between input energy $E_{1}$ of different track shape ratios $k$ the range of slip ratio of outer track $i_{\mathrm{o}}$ was limited from 0.2 to 1 . The figure shows that for the bigger range of slip ratio of outer track $i_{0}$ the input energy $E_{1}$ increases with increment of track shape ratio $k$, i.e. with the decrement of track width $B$. For the small range of slip ratio of outer track, however, the

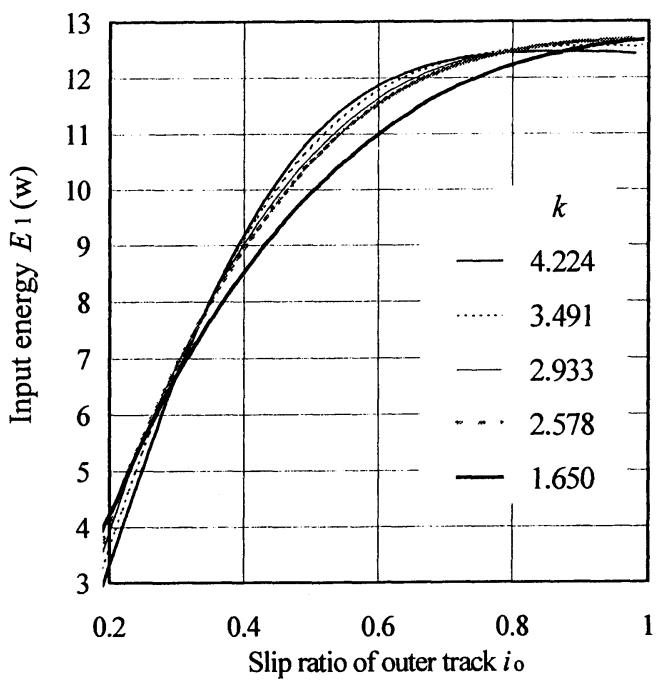

Fig. 16 Influence of track shape ratio $k$ on the input energy $E_{1}$ for different slip ratios of outer track $i_{\mathrm{o}}$

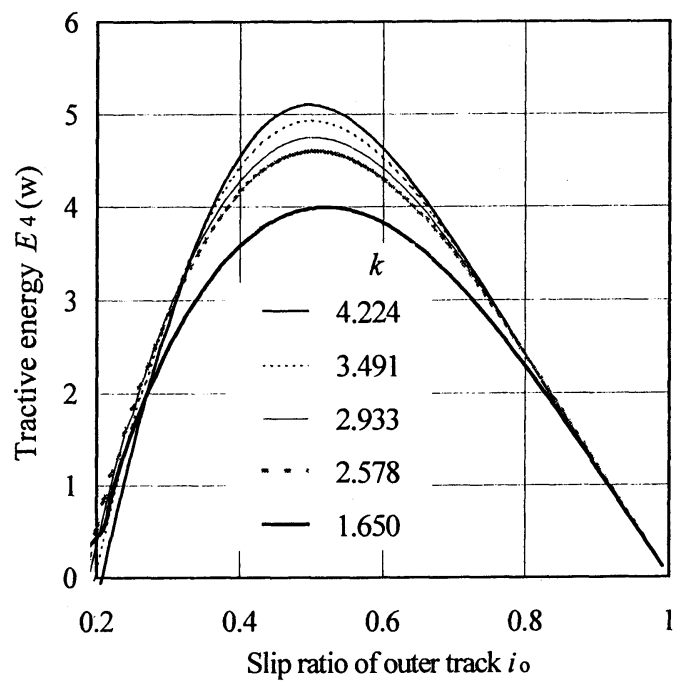

Fig. 17 Influence of track shape ratio $k$ on the tractive energy $E_{4}$ for different slip ratios of outer track $i_{\mathrm{o}}$

tendency is reverse, i.e. the input energy $E_{1}$ increases with decrement of track shape ratio $k$.

Fig. 17 shows the influence of the track shape ratio $k$ on the effective tractive effort energy $E_{4}$ for different track shapes ratio $k$. Similarly to the case of the input energy, the effective tractive energy increase with increment of the track shape ratio $k$, in the larger range of slip ratio of outer track $i_{0}$. The optimum slip ratio of outer track can be found around slip ratio of outer track $i_{0}$ of 0.5 for all the cases of the track shape ratios. It can be observed from the figure that the optimum slip ratio of outer track is larger at smaller track shape ratio $k$, i. e. larger track width $B$. It can be concluded that the 


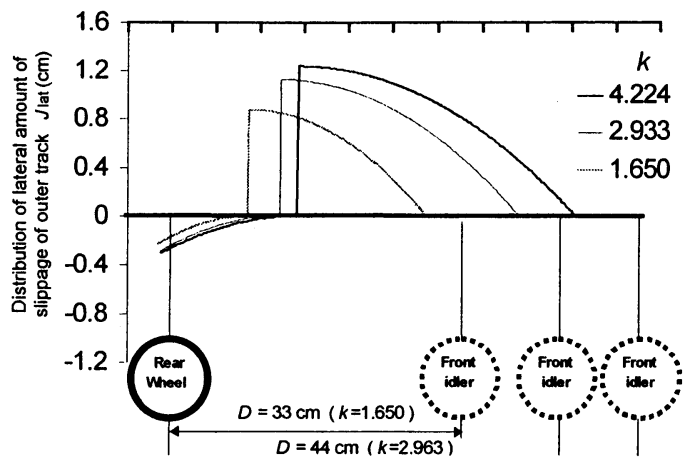

Fig. 18 Influence of track shape ratio $k$ on distribution of lateral amount of slippage of outer track $J_{\text {lat }}$ for the case of slip ratios of outer track $i_{\mathrm{o}}$ of 0.3

track shape ratio $k$ exerts relatively larger effect on the tractive energy $E_{4}$.

Fig. 18 and Fig. 19 show the influence of the track shape ratio $k$ on the distribution of lateral amount of slippage and lateral shear resistance respectively for the case of slip ratio of outer track $i_{0}$ of 0.3 . For better comparison the track shape ratio is limited to only three cases of $k=1.650,2.933$ and 4.224. From the figures it can be observed that the track shape ratio $k$ exerts considerable effect on distribution of lateral amount of slippage and lateral shear resistance.

Fig. 20 shows the influence of the track shape ratio $k$ on the pressure distribution of the inner track for the case of the slip ratio of outer track $i_{0}$ of 0.3 . The figure shows for this case of the slip ratio of outer track $i_{0}$ the pressure of the inner track tends to concentrate on rear wheel as track shape ratio $k$ increases.

\section{CONCLUSION}

The simulation was developed to predict turning characteristics of tracked vehicle turning on fresh concrete. The experiment on the model vehicle running on fresh concrete was then carried out to verify the simulation. The effect of track shape ratio at the same mean contact pressure was investigated and the followings can be concluded for a given fresh concrete-model vehicle: $\mathrm{cm}$

$\begin{array}{lllllllllllll}-5 & 0 & 5 & 10 & 15 & 20 & 25 & 30 & 35 & 40 & 45 & 50 & 55\end{array}$

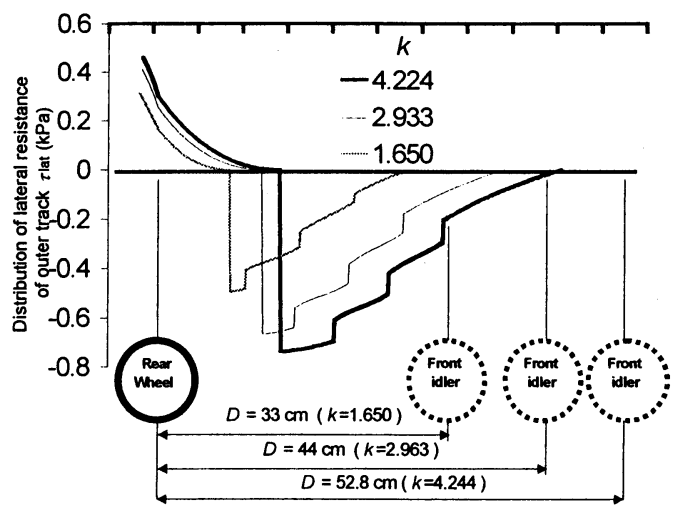

Fig. 19 Influence of track shape ratio $k$ on distribution of lateral shear resistance of outer track $\tau_{\text {lat }}$ for the case of slip ratios of outer track $i_{\mathrm{o}}$ of 0.3

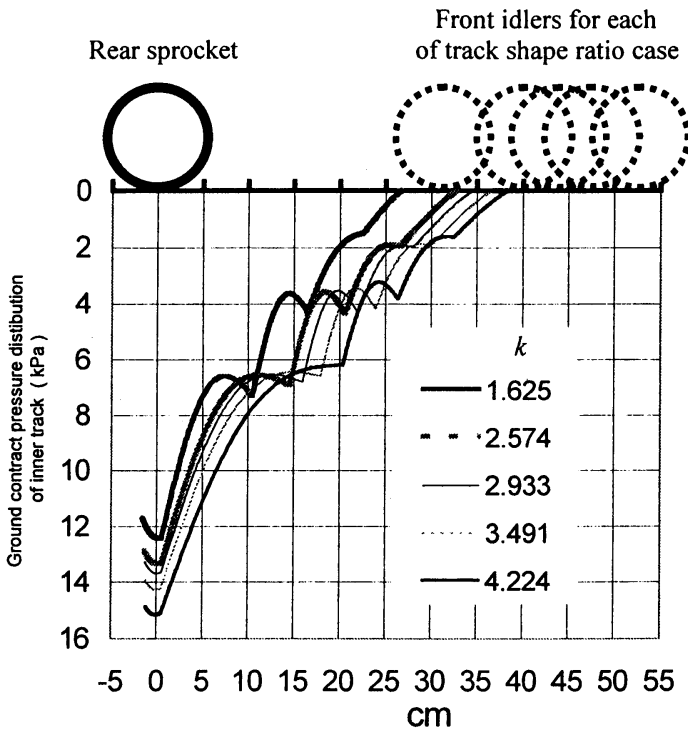

Fig. 20 Influence of track shape ratio $k$ on the ground contact pressure distribution of inner track for the case of slip ratio of outer track $i_{\mathrm{o}}$ of 0.3

(1) In general, the tractive effort $T_{4}$ decreases with the increment of the track shape ratio $k$, i.e. decrement of the track width $B$ for a typical turning motion corresponding to the region of smaller slip ratio of outer track $i_{0}$.

(2) The turning radius $R$ increases with the increment of the track shape ratio $k$, i. e. the decrement of the track width $B$. 
(3) The track shape ratio $k$ exerts considerable influence on the turning moment $M$ in the region of typical turning motion with smaller slip ratio of outer track $i_{0}$. Furthermore, the turning moment $M$ increases with the increment of the track shape ratio $k$, i. e. decrement of the track width $B$.

\section{REFERENCES}

1) Bekker, M. B.: Theory of land locomotion, the mechanics of vehicle mobility, University of Michigan press, pp. 280282

2) Muro, $T$ and Thai, T.D.: Turning Characteristics of a Bulldozer under Traction on a Weak Sandy Terrain, Proceedings of $7^{\text {th }}$ European ISTVS Conference, pp. 102109, 1997.
3) Muro, T. and Thai, T.D.: Numerical Analysis to Predict Turning Characteristics of Rigid Tracked Vehicle under Traction on Loose Sandy Soil, TERRAMECHANICS, Volume 18, The Japanese Society for Terramechanics, pp. 41-48, 1998.

4) William H. Press, Saul A. Teukoisky, William T. Vetterling and Brian P. Flannery: Numerical Recipes in C, the art of scientific computing- second edition, Cambridge University Press, pp. 379-393, 1995.

5) Tran Dang Thai and Tatsuro Muro: Numerical analysis to predict turning characteristics of rigid suspension tracked vehicle, Journal of Terramechanics, Volume 36, No.4, pp.183-196, October 1999.

(Received March 10, 1999)

\section{フレッシュコンクリート上を走行する履帯式車両の旋回特性に及ぼす 履帯形状比の影響}

\author{
トラン ダンタイ・室 達朗・河原荘一郎・平川 学
} について調べることを目的としている. 本報は, 実験と解析結果より, 軟弱地盤上での履帯式車両の旋回特性として, 沈下量, 有効牽引力, 旋回半径, 旋回モーメントおよび車両傾斜角に履帯形状比が及ぼす影響について示してい る. その結果, 履帯幅が狭く履帯長が長くなる程旋回モーメントが大きく旋回半径が大きくなることが判明した. 